\title{
The effect of low-frequency sound stimulation on patients with fibromyalgia: A clinical study
}

\author{
Lili Naghdi MD CCFP ${ }^{1,2}$, Heidi Ahonen PhD MTA ${ }^{1,3}$, Pasqualino Macario DC ${ }^{2}$, Lee Bartel PhD ${ }^{1,4}$
}

\begin{abstract}
L Naghdi, H Ahonen, P Macario, L Bartel. The effect of lowfrequency sound stimulation on patients with fibromyalgia: A clinical study. Pain Res Manag 2015;20(1):e21-e27.
\end{abstract}

BACKGROUND: The search for effective treatments for fibromyalgia (FM) has continued for years. The present study premises that thalamocortical dysrhythmia is implicated in fibromyalgia and that low-frequency sound stimulation (LFSS) can play a regulatory function by driving neural rhythmic oscillatory activity.

OBJECTIVE: To assess the effect of LFSS on FM.

METHOD: The present open-label study with no control group used a repeated-measures design with no noncompleters. Nineteen female volunteers (median age 51 years; median duration of FM 5.76 years) were administered 10 treatments (twice per week for five weeks). Treatments involved $23 \mathrm{~min}$ of LFSS at $40 \mathrm{~Hz}$, delivered using transducers in a supine position. Measures (repeated before and after treatment) included the Fibromyalgia Impact Questionnaire, Jenkins Sleep Scale, Pain Disability Index, sitting and standing without pain (in minutes), cervical muscle range of motion and muscle tone. Mean percentages were calculated on end of treatment selfreports of improvement on pain, mood, insomnia and activities of daily living. RESULTS: Significant improvements were observed with median scores: Fibromyalgia Impact Questionnaire, $81 \%(\mathrm{P}<0.0001)$; Jenkins Sleep Scale, 90\% $(\mathrm{P}<0.0001)$; and Pain Disability Index, 49.1\% $(\mathrm{P}<0.0001)$. Medication dose was reduced in $73.68 \%$ of patients and completely discontinued in $26.32 \%$. Time sitting and standing without pain increased significantly $(\mathrm{P}<0.0001)$. Cervical muscle range of motion increased from $25 \%$ to $75 \%(\mathrm{P}=0.001)$, while muscle tone changed from hypertonic to normal $(\mathrm{P}=0.0002)$.

CONCLUSION: In the present study, the LFSS treatment showed no adverse effects and patients receiving the LFSS treatment showed statistically and clinically relevant improvement. Further phase 2 and 3 trials are warranted.

Key Words: $40 \mathrm{~Hz}$; Fibromyalgia; Low frequency; Music medicine; Neural circuit dysrhythmia; Rhythmic sensory stimulation

Fibromyalgia (FM) is a syndrome involving diffuse body pain with assoCiations of fatigue, sleep disturbance, cognitive changes, mood disturbance and other variable somatic symptoms (1). FM is a common pain disorder estimated to affect $2 \%$ to $4 \%$ of the population, of whom $80 \%$ are women (2); it is most prevalent in the third to fifth decade of life.

Pain is the primary complaint in patients with FM. Fatigue is the most common associated complaint and is present in $>90 \%$ of patients (1). Sleep abnormalities result in changes in sleep latency, sleep disturbance and fragmented sleep, leading to impaired daytime function $(3,4)$. Mood disorders, including depression and anxiety, are present in up to three-quarters of patients with FM (5). Due to the nature of FM, many patients experience problems with their activities of daily living (ADL) and poor quality of life, and may end up on disability, which has a significant impact on them and their families. In the United States, the cost

\section{L'effet de la stimulation sonore à basse fréquence che $z$ les patients atteints de fibromyalgie : une étude clinique}

HISTORIQUE : La recherche de traitements efficaces contre la fibromyalgie (FM) se poursuit depuis des années. Selon la prémisse de la présente étude, la dysrythmie thalamocorticale contribue à la FM et la stimulation sonore à basse fréquence (SSBF) peut avoir une fonction régulatrice en stimulant l'activité rythmique oscillatoire neuronale.

OBJECTIF : Évaluer l'effet de la SSBF sur la FM.

MÉTHODOLOGIE : La présente étude ouverte sans groupe témoin a fait appel à des mesures répétées que tous ont terminées. Dix-neuf volontaires de sexe féminin (âge médian de 51 ans; durée médiane de FM de 5,76 ans) se sont fait administrer dix traitements (deux fois par semaine pendant cinq semaines). Ces traitements consistaient en une SSBF de $40 \mathrm{~Hz}$ pendant 23 minutes, transmise par transducteurs aux patientes en décubitus dorsal. Les mesures (répétées avant et après le traitement) incluaient le questionnaire sur les effets de la fibromyalgie, l'échelle de sommeil de Jenkins, l'indice d'incapacité causée par la douleur, la période de position assise et debout sans ressentir de douleur (en minutes), l'amplitude de mouvement des muscles cervicaux et le tonus musculaire. Les pourcentages moyens étaient calculés d'après les autodéclarations d'atténuation de la douleur, de l'humeur, de l'insomnie et des activités de la vie quotidienne à la fin du traitement.

RÉSULTATS : Les chercheurs ont observé des améliorations considérables aux indices médians : questionnaire sur les effets de la fibromyalgie, $81 \%(\mathrm{P}<0,0001)$; échelle de sommeil de Jenkins, $90 \%$ ( $\mathrm{P}<0,0001)$, et indice d'incapacité de la douleur, $49,1 \%(\mathrm{P}<0,0001)$. La dose du médicament était réduite chez 73,68 \% des patientes et complètement abandonnée chez 26,32 \% d'entre elles. La période en position assise et debout sans ressentir de douleur augmentait considérablement $(\mathrm{P}<0,0001)$. L'amplitude de mouvement des muscles cervicaux passait de $25 \%$ à $75 \%(\mathrm{P}=0,001)$, tandis que le tonus musculaire passait d'hypertonique à normal $(\mathrm{P}=0,0002)$. CONCLUSION : Dans la présente étude, le traitement par SSBF ne provoquait pas de réactions indésirables, et les patientes qui le recevaient présentaient une amélioration pertinente sur le plan statistique et clinique. Des essais de phase 2 et de phase 3 s'imposent.

for service utilization in an individual FM patient was $>\$ 2000$ in 1997, with reports in the order of $\$ 4000$ per year per patient for Canada and Europe (6-9). There is currently no cure for FM. Ideal management includes both nonpharmacological and pharmacological treatments using a multimodal approach, with active patient participation fostered by a strong patient-centred locus of control (10).

Abnormalities in pain processing have been identified at various levels in the peripheral, central and sympathetic nervous systems, as well as the hypothalamo-pituitary-adrenal axis stress-response system. Documented abnormalities include evidence of peripheral sensitization and wind-up phenomenon, central sensitization with changes in functional magnetic resonance imaging and single-photon emission computed tomography scans of the brain, increased levels of substance $\mathrm{P}$ in the cerebrospinal fluid and impairment of descending

\footnotetext{
${ }^{1}$ Music and Health Research Collaboratory, University of Toronto, Toronto; ${ }^{2}$ Sound Therapy Centre of Vaughan, Vaughan; ${ }^{3}$ Conrad Institute for

Music Therapy Research, Wilfrid Laurier University, Waterloo; ${ }^{4}$ Faculty of Music, University of Toronto, Toronto, Ontario

Correspondence: Dr Lee Bartel, Faculty of Music, University of Toronto, 80 Queen's Park Crescent, Toronto, Ontario M5S 2C5. Telephone

416-489-2822, e-mail lbartel@chass.utoronto.ca
} 
noxious inhibitory control $(11,12)$. Some forms of chronic pain appear to alter thalamocortical connections, causing a disruption of thalamic feedback and the possibility that chronic pain may be related to thalamocortical dysrhythmia (TCD) (13). There is increasing evidence for altered thalamic function in pain patients with chronic pain $(14,15)$ and FM (16-18). Previous literature suggests that lowered thalamic function in FM patients represents a ceiling effect of descending pain inhibition (16) maintained by the persistent excitatory input of pain signals. Support for this mechanism was found in a study in which normalization of reduced thalamic activity was observed in response to analgesic treatment (nerve blockade) in patients with peripheral neuropathic pain (19). In TCD, normal thalamocortical resonance is disrupted by changes in the behaviour of neurons in the thalamus.

\section{Music and pain}

Pain theory and music: Although there have been numerous studies investigating music and pain (20), few have been adequately theorized in relation to dominant pain theories to explain why music reduces pain. This may be due, in part, to the inadequacy of early pain theories, such as the discredited specificity theory, intensity theory and pattern theory (21), and to weaknesses in the gate control theory (GCT), which has been been proposed as the basis for some music effects. Although GCT (22) postulated that affective and cognitive responses, such as music-responsive attention and psychological states, influenced the gate through efferent descending fibres, research has shown that GCT oversimplified neural systems (21). Melzack (23) proposed a more adequate pain theory that explains the effects of music as a unified brain mechanism-based body-self neuromatrix (NM). Sensory, cognitive and affective dimensions are fully credited with affecting pain perception, and these dimensions are subject to cognitive-evaluative (attention, expectation, anxiety, valence) and motivational-affective (neurotransmitter, hormonal, limbic) inputs. Although exact mechanisms are not yet understood, NM offers an explanation as to why functions of music, such as distraction, stress and anxiety reduction, and aesthetic pleasure, reduce pain perception. Although GCT was superseded by NM to explain typical music functions, GCT does explain why stimulation of touch fibres can reduce pain perception, as has been demonstrated with certain applications of lowfrequency sound stimulation (LFSS), which induces mechanical vibrotactile stimulation of mechanoreceptors and spinal cord functioning, not unlike electrical skin and spinal cord stimulation (24). However, neither the GCT nor NM allow explanation of experiential phenomena, including pain, associated with rhythmic oscillatory coherence $(25,26)$ and how music as rhythmic vibration can drive oscillatory coherence. The correlation of thalamocortical oscillatory dysrhythmia with pain has been demonstrated $(27,28)$ but no definitive theory has been established

Cognitive and affective effects of music: Given the role that neurotransmitters, hormones and the limbic system play in pain according to the NM theory, it is highly relevant that music has been shown to affect the release of endorphins $(29-37)$, dopamine $(38,39)$ and serotonin $(40,41)$, and decrease cortisol levels $(39,42-47)$. A recent review (45) of 400 published scientific articles investigating music as medicine found strong evidence that music has effects on brain chemistry, has mental and physical health benefits on management of mood and stress reduction, and that it is the rhythmic stimulation of music, rather than the melody, that has the greatest antipain effect in the brain.

GCT and sensory effect of sound: GCT suggests that stimulating the touch senses in the nerve origin region of pain will serve to 'close the gate' to the transmission of pain. LFSS, variously known as vibroacoustic or physioacoustic therapy, stimulates the mechanoreceptors in the body and cellular structures more deeply, thereby potentially serving to block pain transmission. LFSS, usually delivered through chairs or beds specially fitted with low frequency transducers, has been found to improve mobility (48), increase circulation (49), decrease low-density lipoprotein levels and blood pressure $(50)$, help decrease pain $(49,50)$, and reduce muscle strain and stiffness (49).

Studies involving LFSS have examined specific pain conditions: rheumatoid arthritis using $40 \mathrm{~Hz}(51)$; polyarthritis in hands and chest using $40 \mathrm{~Hz}$ (52,53); low back pain using $52 \mathrm{~Hz}(52,53)$; knee replacement pain (54); postoperative gynecological pain (55); menstrual pain and dysmenorrhea using $52 \mathrm{~Hz}(52,53)$; and sports injuries $(52,53,56)$. Music and FM: The effect of music on pain though sensory, cognitive and affective dimensions has been demonstrated. The effect of LFSS on various pains conditions has also been demonstrated. Little research has specifically focused on the effects of music or LFSS on FM. Chesky et al (57) studied the immediate effects of music and musically fluctuating vibration $(60 \mathrm{~Hz}$ to $300 \mathrm{~Hz})$ on tender point pain in patients with FM. According to the results, musically fluctuating vibration failed to alter pain perception in FM. Onieva-Zafra et al (58) studied the effect of four weeks of daily music listening to unspecified 'classical' music mixed with salsa music. The music listening group showed significant reductions in pain, measured using the McGill Pain Scale (sensory $[\mathrm{P}=0.04]$ and evaluative $[\mathrm{P}=0.02])$. The control group received no treatment and showed no significant change. Müller-Busch and Hoffmann (59) studied chronic pain patients, including patients with FM, with a treatment of active music therapy using unspecified performed music. Results found significant reduction in reported pain intensity but no change in depression and anxiety scores. Leão and da Silva (60) found that women with chronic pain experienced less pain $(\mathrm{P}=0.001)$ after listening to classical music. The few studies of sound and FM that exist primarily draw on cognitive and affective effects of music. LFSS and FM research has not previously been theorized and conducted as in the present study.

\section{TCD as a basis for chronic pain}

TCD is an abnormal condition of the oscillatory network between the thalamus and cortex characterized by an increase in resonant low-frequency oscillations in the theta range, with attendant 'dark' areas of reduced $40 \mathrm{~Hz}$ coherent oscillation in the cortex. TCD disrupts normal intrabrain connectivity and results in disturbed sensation, cognition, affect and motor performance (27,61-63). One of the conditions known to be associated with TCD is chronic pain (63-67). Specifically, reduced connectivity between the thalamus and the orbitofrontal cortex has been observed in FM patients (68). Although there is not complete scientific agreement on the basis of FM, the present study is based on the assumption that it is at least partially neurogenic and that TCD is, therefore, implicated.

\section{Rhythmic sensory stimulation}

Music essentially consists of vibration at multiple frequencies. When frequencies are beyond $16 \mathrm{~Hz}$, they are heard as pitches, but each individual sound wave can be considered to be a separate stimulative event. Consequently, a pitch of $40 \mathrm{~Hz}$, heard as a low pitch close to the lowest ' $\mathrm{E}$ ' on the piano, is not a singular stimulation, but rather exerts 40 stimuli per second. When this stimulus is applied to the ears as sound waves it 'drives' a brain response through the auditory system. The same effect can be obtained with an isochronous sound created with amplitude modulation (69). When the $40 \mathrm{~Hz}$ sound is processed by transducers installed in a chair, the effect is felt as vibrotactile and can 'drive' a response through the somatosensory system. The effect can also be created and brain response observed with mechanical vibration (70-72). Rhythmic sensory stimulation (RSS) similarly extends to the visual domain (73-75).

TCD as a malfunction of coherent rhythmic oscillation should be subject to 'stabilization' through rhythmic driving of oscillatory neural activity. Llinás and Ribary (76) showed a reset of the thalamocortical oscillation with auditory stimulation. Ross et al (70) showed an effect of $40 \mathrm{~Hz}$ steady-state oscillation with vibratory stimulus. Theoretically, the effect of RSS to regulate the TCD related to neurogenic pain is the foundational premise of the present study.

The present study speculates that TCD is implicated in FM and that RSS can play a rehabilitative role through driving neural rhythmic oscillatory activity, and resetting or regulating the dysrhythmia. However, RSS, when applied as full body vibrotactile stimulation, as in the present study, may also contribute to a reduction in FM symptoms by blocking pain perception through GCT, or by improving lymphatic drainage and lowering vascular congestion (77). 
TABLE 1

Demographic and medical characteristics at recruitment

\begin{tabular}{|c|c|c|c|}
\hline & & \multicolumn{2}{|c|}{ Range } \\
\hline & & Minimum & Maximum \\
\hline Age, years, median (q1, q3) & $51(46,56)$ & 38 & 65 \\
\hline \multicolumn{4}{|l|}{ Sex, n (\%) } \\
\hline Female & $19(100)$ & & \\
\hline Male & $0(0)$ & & \\
\hline $\begin{array}{l}\text { FM diagnostic criteria } \\
\text { assessment, median (q1, q3) }\end{array}$ & $15(10,19)$ & 8 & 19 \\
\hline Duration of FM, years, mean \pm SD & $5 \pm 2.9$ & 0.16 & 16 \\
\hline Main FM symptom & & \multicolumn{2}{|c|}{ Pain (100\%) } \\
\hline
\end{tabular}

FM Fibromyalgia; q Quartile

TABLE 2

Fibromyalgia Impact Questionnaire (FIQ) and Jenkins Sleep Scale (JSS) results

\begin{tabular}{lccccccc}
\hline & & & \multicolumn{2}{c}{ Range } & Signed & \\
\cline { 3 - 5 } Test & Median & Mean \pm SD & Minimum & Maximum & rank & P \\
\hline FIQ initial & 88.8 & $85.8 \pm 10.9$ & 47.0 & 94.9 & & \\
FIQ final & 16.8 & $19.9 \pm 13.8$ & 3.3 & 55.5 & & \\
Difference & 72 & 65.9 & & & 95 & $<0.0001$ \\
JSS initial & 20 & $19.16 \pm 2.36$ & 10 & 20 & & \\
JSS final & 2 & $4.11 \pm 4.21$ & 0 & 16 & & \\
Difference & 18 & 15.05 & & & 95 & $<0.0001$ \\
\hline
\end{tabular}

TABLE 3

Pain Disability Index reduction

\begin{tabular}{lcccc}
\hline & Minimum & Maximum & Mean \pm SD & P \\
\hline $\begin{array}{l}\text { Reduction in Pain } \\
\text { Disability Index score }\end{array}$ & 11.0 & 44.0 & $26.89 \pm 9.67$ & $<0.0001$ \\
\hline
\end{tabular}

\section{METHODS}

\section{Participants}

Following Research Ethics Board approval from Wilfrid Laurier University (Waterloo, Ontario), a total of 19 female volunteer subjects, with a median age of 51 years and median duration of FM of 5.76 years, were recruited for the present study. At recruitment, patients' FM diagnostic criteria assessment (78) was 15 (median) with a minimum of eight and maximum of 19 . Information regarding study design, treatments, contraindications and theoretical basis for the therapy was given to each participant. Informed consent was obtained from the participants. Table 1 shows the characteristics of the participants.

\section{Intervention}

The treatment consisted of two sessions per week for five weeks, for a total of 10 treatments. At each session, patients received 23 min of LFSS at a $40 \mathrm{~Hz}$ frequency (79), delivered with the SL5 lounge from Nexneuro (USA). The power level of the sound was the same for all subjects (decibel level not measured). They were not specifically instructed to do anything other than lie back and relax. Participants experienced a mild vibrotactile sensation on their body as well as a low-level hum. No patient reported any discomfort or annoyance. Blood pressure and pulse rate were checked and documented in every session before and after the treatment while patients were on the lounge.

\section{Instrumentation - assessment and outcome measures}

Initial assessment: An initial assessment was conducted by a medical doctor consisting of a complete physical examination addressing the history of previous therapies, most offending symptom, and medications and dosage used. Subjects were asked to give a subjective rating of pain, mood, insomnia and ADL. The same medical doctor then examined the participants' ability to sit and stand without pain (measured as length of time in minutes) based on participant self-report, referenced to tasks such as watching television or washing dishes. No

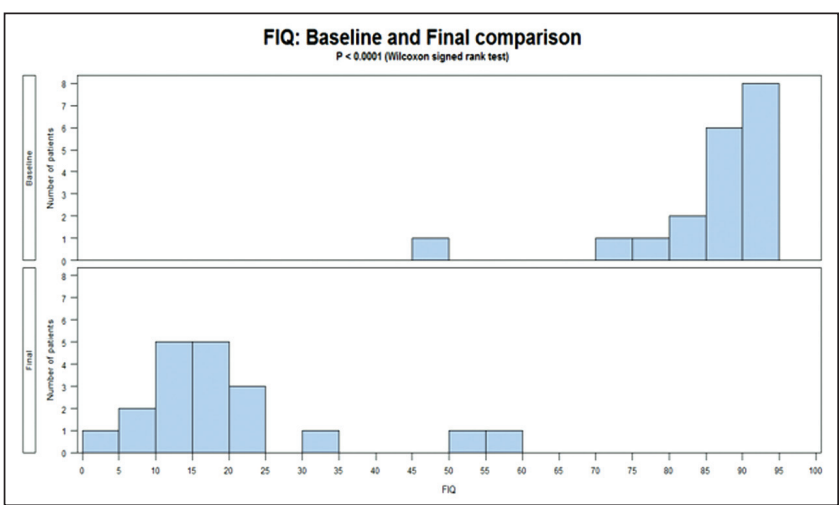

Figure 1) Fibromyalgia Impact Questionnaire (FIQ) before and after comparison

standardized scale was used. Each subject was then examined separately by a doctor of chiropractic medicine to determine range of motion (ROM) and muscle tone in different areas of their body. Each subject then completed the Fibromyalgia Impact Questionnaire (FIQ) (80), the Jenkins Sleep Scale (JSS) (81) and the Pain Disability Index (PDI) (82,83). This comprehensive pretreatment assessment was performed as an indicator of steady baseline condition on which to make treatment effect comparisons.

Although not part of the standard diagnostic criteria for FM, physical dysfunction is associated with the constellation of signs and symptoms of FM patients. ROM was included in the present study to identify whether functional improvements were achieved with vibroaccoustic therapy. Other studies have used ROM measurements to quantify similar improvements of physical function when performing different forms of therapies $(84,85)$. Similarly, muscle tone was examined as an outcome based on an extensive literature describing how pathophysiology can be expressed as pain, increased muscle tone and tension (86-88). One study by Kokebie et al (89) quantified this presentation using a pressure gauge. Furthermore, there are several studies that have used this sign as an indicator for condition improvement, albeit through other forms of therapeutic techniques $(90,91)$.

Outcome assessment: Immediately after the 10th LFSS treatment session, each participant was assessed on the 12 measures used in the initial assessment.

Second outcome assessment: Precisely two weeks after their 10th LFSS session, during which they received no LFSS treatment, subjects were further assessed regarding when symptoms reoccurred (in days), with a retrospective self-report related to pain and sleep and, of the standardized measures, only the PDI. The JSS was not reassessed because its standardized follow-up interval is one month.

\section{Analysis}

The present study used a repeated measures design. There were no noncompleters. The Wilcoxon signed rank test (WSR) was used compare initial and final values on FIQ, JSS, PDI, length of ability to sit and stand without pain (in minutes), ROM and cervical muscle tone. Mean percentages were calculated on self reports of improvement on pain, mood, insomnia and $\mathrm{ADL}$

\section{RESULTS AND DISCUSSION}

Highly significant results were found in the present study; thus, caution needs to be taken in interpretation and we urge follow-up research with a blinded controlled trial. Pain is a highly subjective experience and difficult to measure objectively. The impact of pain is more amenable to measurement; therefore, three measures of the impact of pain were used: the FIQ, JSS and PDI. Table 2 presents the before-treatment (score 88.8 ) to after-treatment (score 16.8 ) reduction in pain impact $(81 \%)$ measured using the FIQ, which was statistically significant $(\mathrm{P}<0.0001$; WSR). A comparable impact was measured using the PDI (Table 3) with a $49 \%$ before-after treatment reduction $(\mathrm{P}<0.0001$; WSR). Sleep is 


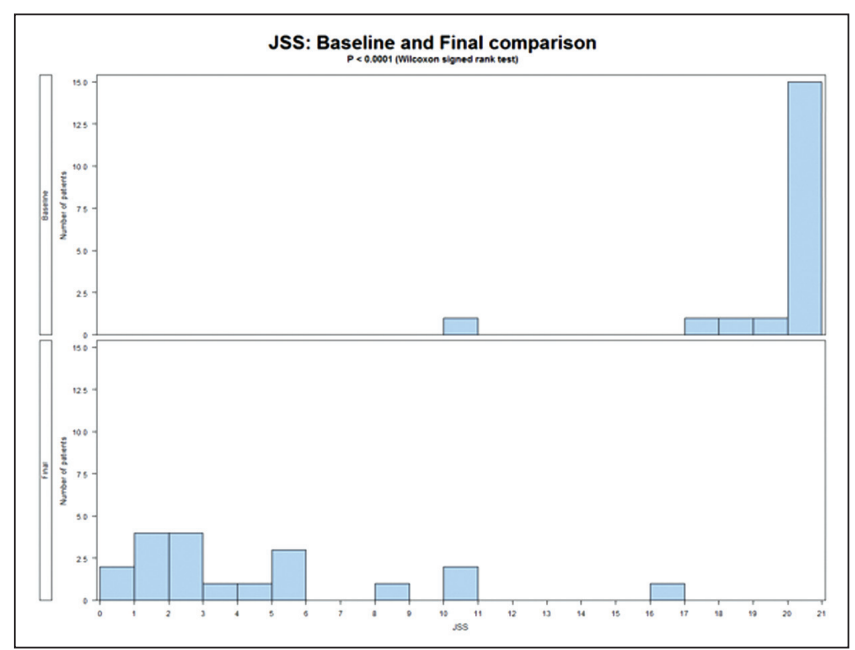

Figure 2) Jenkins Sleep Scale (JSS) before and after comparison

TABLE 4

Self-report following treatment

\begin{tabular}{lrrc}
\hline & & \multicolumn{2}{c}{ Range } \\
\cline { 3 - 4 } & & & \\
\hline Medication intake, $\mathrm{n}(\%)$ & $14(73.68)$ & & \\
$\quad$ Reduced dosage & $5(26.32)$ & & \\
$\quad$ Stopped totally & & & \\
Subjective improvement, \%, & & & \\
$\quad$ median (q1, q3) & $70(50,80)$ & 35 & 90 \\
Pain & $65(45,85)$ & 35 & 100 \\
Mood & $65(40,85)$ & 30 & 95 \\
Insomnia & $70(50,80)$ & 35 & 90 \\
Activities of daily living & & & \\
Global impression of change, $\mathrm{n}(\%)$ & $0(0)$ & & \\
$\quad$ Negative & $2(10.53)$ & & \\
$\quad$ Slightly better & $8(42.11)$ & \\
$\quad$ Much better & $9(47.37)$ & & \\
Very much better &
\end{tabular}

q Quartile

strongly affected by FM, with some studies reporting $90 \%$ of patients having disturbed sleep $(92,93)$. The before-treatment JSS median score of 20 was reduced after treatment to 2, an improvement of $90 \%$ $(\mathrm{P}<0.0001$; WSR) (Table 1). Figures 1 and 2 graphically illustrate the changes in FIQ and JSS. Although the after-treatment scores are significantly different than before treatment, there is less uniformity in the 'after' scores, as indicated by the greater scatter in Figures 1 and 2 and by the higher SDs in Table 1.

A highly important indicator of the impact of FM is the number of days patients miss work. This single scale from the FIQ indicated that the median days of missed work before treatment was four days per week, which was reduced to one day per week after the treatment $(\mathrm{P}<0.0001 \mathrm{WSR})$.

A strong indicator of pain experienced is the amount of medication used. Table 4 shows that after treatment, $73.68 \%$ of patients reported using a reduced dose of medication and $26.32 \%$ of patients had completely discontinued use of pain medicine.

Table 4 shows patients' subjective self-report of the degree of improvement during the course of treatment on pain, mood, insomnia and ADL. Median scores were are improved by $>65 \%$. Subjective assessment of pain and ADL are $>70 \%$ in median. Patients were asked for a global impression of change in their condition following treatment. Slightly less than $90 \%$ reported their condition to be much or very much better, with none reporting it being worse.

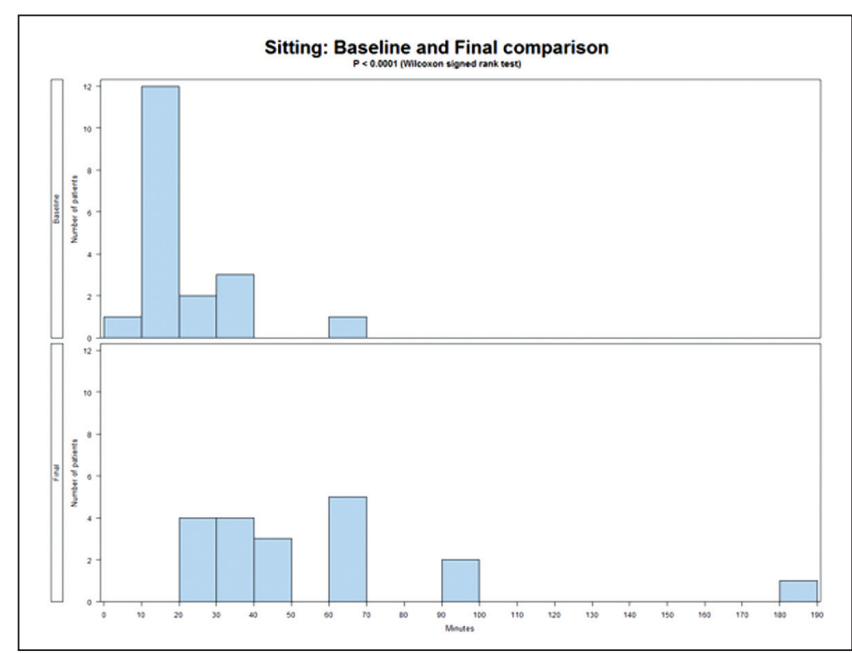

Figure 3) Length of time sitting before and after treatment

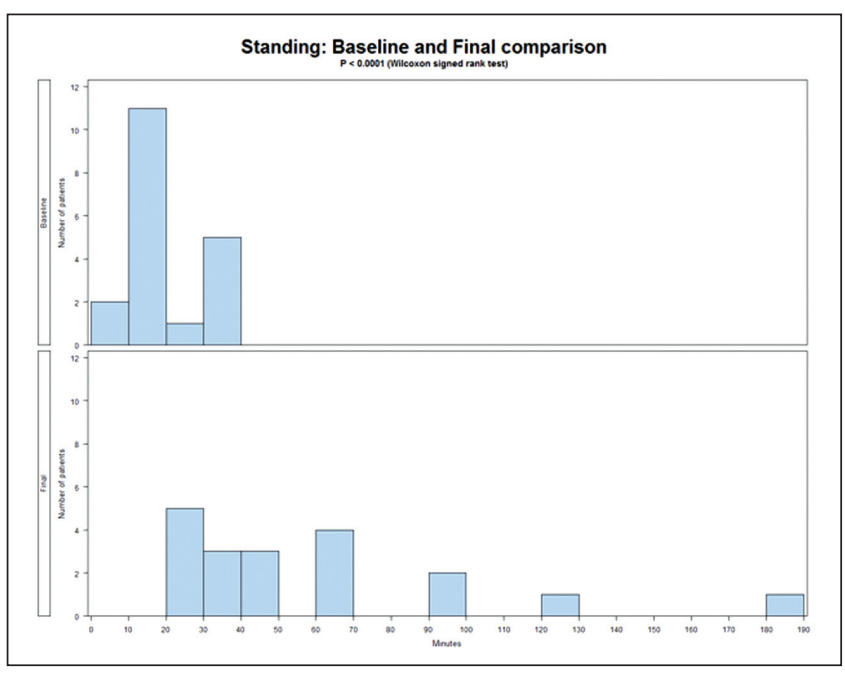

Figure 4) Length of time standing before and after treatment

One way to triangulate the patients' self report of pain reduction is with two test items from FIQ - the single-scale pain assessment and the single-scale tiredness reduction assessment. On the FIQ pain scale, the median pain level was 9 before treatment and 2 after treatment $(\mathrm{P}<0.0001$; WSR $)$. The FIQ tiredness scale showed a reduction from 10 before treatment to 2 after treatment ( $P<0.0001$; WSR).

Because FM is known to cause stiffness, and pain decreases length of time individuals can stand or sit, sitting, standing and ROM tests were used. Table 5 reports the results of the physical assessments before and after treatment. The length of time patients can sit increased significantly $(\mathrm{P}<0.0001)$, as did the length of time standing $(\mathrm{P}<0.0001)$. These results are presented in Figures 3 and 4.

Table 5 presents the changes in cervical ROM and cervical tone before and after treatment. Figure 5 shows that most patients (11 of 19) had 25\% ROM and none had full ROM at baseline, while nine of 19 patients had $>75 \%$ ROM and only three of 19 had $<25 \%$ ROM after treatment. Similarly, Figure 6 shows that 13 of 19 patients were more hypertonic and none had normal tone at baseline, while there were seven patients with normal tone, six who were hypertonic and none who were more hypertonic after treatment.

The median cervical muscle ROM increased from a baseline of $25 \%$ to $75 \%$ following treatment $(\mathrm{P}=0.001$; WSR), while muscle tone changed from hypertonic at baseline to normal tone ( $\mathrm{P}=0.0002$; WSR).

With highly significant reductions in pain and impact of FM on quality of life, it is important to observe the return of FM symptoms following 
TABLE 5

Physical ability results

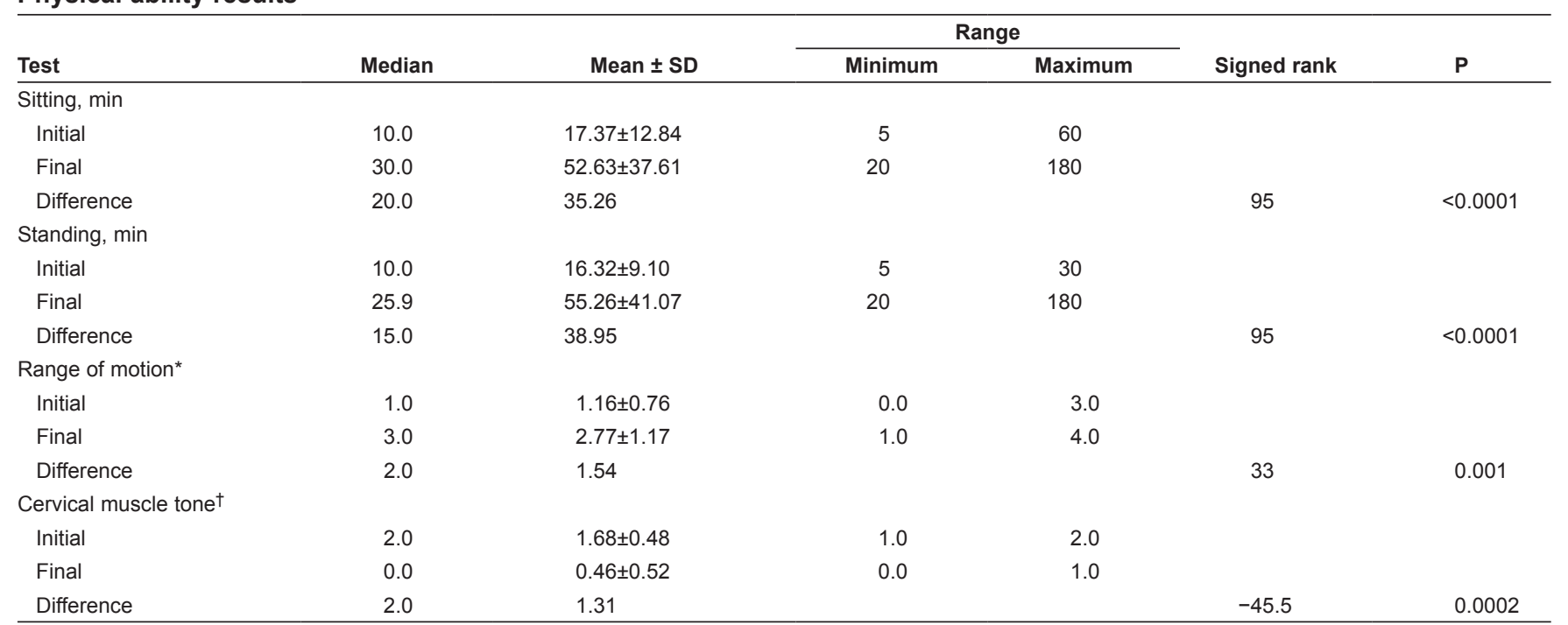

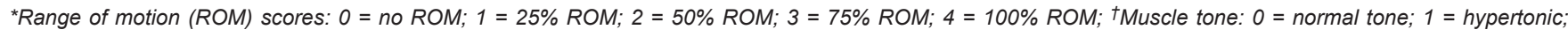
$2=$ more hypertonic

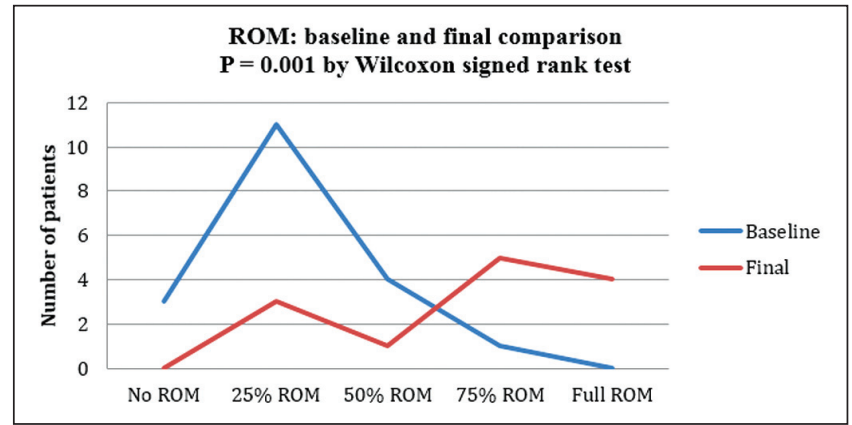

Figure 5) Range of motion (ROM) before and after treatment

the end of treatment. Table 6 presents results of symptom recurrence. Although three patients (15.8\%) reported no recurrence of symptoms within 14 days, $84.2 \%$ experienced a recurrence of pain (68.4\%) or sleep disturbance $(17.8 \%)$. For patients with recurring pain, the pain recurred within a mean of eight days (minimum seven days, maximum 14 days). For patients with recurring insomnia, the symptom recurred within a mean of 10 days (minimum seven days, maximum 14 days).

\section{CONCLUSION}

The results of the present study suggest that LFSS may be beneficial in the treatment of FM. It is important to note that the present study was an open-label investigation, with no group or baseline control. The contribution to quality of life appears to be highly significant and the reduction in medication important. The mechanisms by which the effects were obtained in the present study cannot be definitely identified, but highlight the need for further exploration of the effect of LFSS on muscular and joint mobility through cellular stimulation and the need for brain imaging to determine the effect of LFSS on possible neural dysrhythmias that may underlie FM. Because personal-choice music listening has been shown to have an effect on pain, further research should explore variants of the treatment used including the combination of LFSS with music listening and the use of auditory isochronous $40 \mathrm{~Hz}$ sound as an alternative or adjunct to LFSS. Furthermore, it must be noted that the present analysis was a pilot study that had limitations as an open-label study without an initial baseline, with limited follow-up and with no comparison group. However, the results are strong enough to warrant further research and exploration of continued dosing effects.

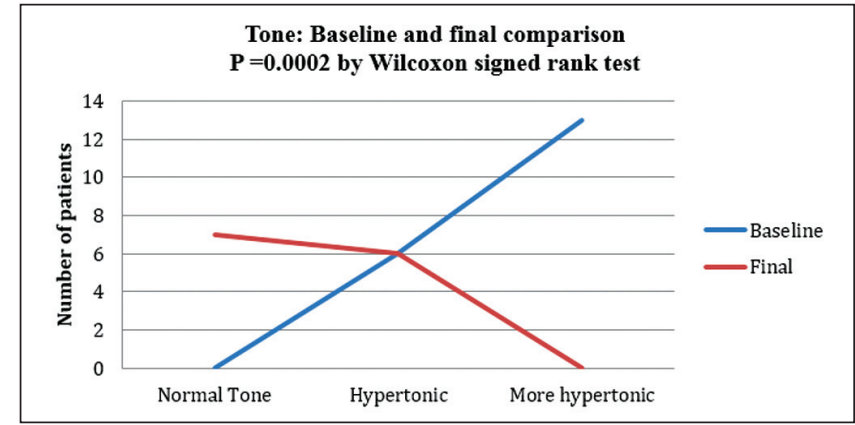

Figure 6) Muscle tone before and after treatment

\section{TABLE 6}

Recurrence of symptoms following treatment

\begin{tabular}{lcccc}
\hline First recurrence of & & & \multicolumn{2}{c}{ Range } \\
\cline { 4 - 5 } symptoms (total $\mathbf{n = 1 9 )}$ & & $\mathbf{q 1}, \mathbf{q} 3$ & Minimum & Maximum \\
\hline Pain, $\mathrm{n}(\%)$ & $13(68.4)$ & & & \\
$\quad$ Time to recurrence, days & 8 & 7,10 & 7 & 14 \\
Insomnia, $\mathrm{n}(\%)$ & $3(15.8)$ & & & \\
$\quad$ Time to recurrence, days & 10 & 7,11 & 7 & 11 \\
None, $\mathrm{n}(\%)$ & $3(15.8)$ & & & \\
\hline
\end{tabular}

q Quartile

ACKNOWLEDGEMENTS: The authors gratefully acknowledge the assistance of Chang Ye in the statistical analysis of the data.

FUNDING: Conrad Institute for Music Therapy Research, Wilfrid Laurier University, Waterloo, Ontario.

\section{REFERENCES}

1. Mease P, Arnold LM, Choy EH, et al. Fibromyalgia syndrome module at OMERACT 9: Domain construct. J Rheumatol 2009;36:2318-29.

2. Wolfe F, Ross, K, Anderson J, Russell IJ, Hebert L. The prevalence and characteristics of fibromyalgia in the general population. Arthritis Rheum 1995;38:19-28.

3. Osorio CD, Gallinaro AL, Lorenzi-Filho G, Lage LV. Sleep quality in patients with fibromyalgia using the Pittsburgh Sleep Quality Index. J Rheumatol 2006;33:1863-5. 
4. Moldofsky $\mathrm{H}$. The significance of the sleeping-waking brain for the understanding of widespread musculoskeletal pain and fatigue in fibromyalgia syndrome and allied syndromes. Joint Bone Spine 2008;75:397-402.

5. Epstein SA, Kay G, Clauw D, et al. Psychiatric disorders in patients with fibromyalgia. A multicenter investigation. Psychosomatics 1999:40:57-63.

6. Lachaine J, Beauchemin C, Landry PA. Clinical and economic characteristics of patients with fibromyalgia syndrome. Clin J Pain 2010;26:284-90.

7. Penrod JR, Bernatsky S, Adam V, Baron M, Dayan N, Dobkin PL. Health services costs and their determinants in women with fibromyalgia. J Rheumatol 2004;31:1391-8.

8. Rivera J, Rejas J, Esteve-Vives J, et al. Resource utilisation and health care costs in patients diagnosed with fibromyalgia in Spain. Clin Exp Rheumatol 2009;27(5 Suppl 56):S39-45.

9. Wolfe F, Anderson J, Harkness D, et al. A prospective, longitudinal, multicenter study of service utilization and costs in fibromyalgia. Arthritis Rheum 1997;40:1560-70.

10. Rossy LA, Buckelew SP, Dorr N, et al. A meta-analysis of fibromyalgia treatment interventions. Ann Behav Med 1999;21:180-91.

11. Perrot S, Dickenson AH, Bennett RM. Fibromyalgia: Harmonizing science with clinical practice considerations. Pain Pract 2008;8:177-89.

12. Julien N, Goffaux P, Arsenault P, Marchand S. Widespread pain in fibromyalgia is related to a deficit of endogenous pain inhibition. Pain 2005;114:295-302.

13. Cauda F, Sacco K, D'Agata F, et al. Low-frequency BOLD fluctuations demonstrate altered thalamocortical connectivity in diabetic neuropathic pain. BMC Neurosci 2009;26:138.

14. Hsieh JC, Belfrage M, Stone-Elander S, Hansson P, Ingvar M. Central representation of chronic ongoing neuropathic pain studied by positron emission tomography. Pain 1995;63:225-36.

15. Iadarola MJ, Max MB, Berman KF, et al. Unilateral decrease in thalamic activity observed with positron emission tomography in patients with chronic neuropathic pain. Pain 1995;63:55-64.

16. Gracely RH, Petzke F, Wolf M, Clauw D. Functional magnetic resonance imaging evidence of augmented pain processing in fibromyalgia. Arthritis Rheum 2002;46:1333-43.

17. Kwiatek R, Barnden L, Tedman R, et al. Regional cerebral blood flow in fibromyalgia: Single-photon-emission computed tomography evidence of reduction in the pontine tegmentum and thalami. Arthritis Rheum 2000;43:2823-33.

18. Mountz J, Bradley L, Modell J, et al. Fibromyalgia in women. Abnormalities of regional cerebral blood flow in the thalamus and the caudate nucleus are associated with low pain threshold levels. Arthritis Rheum 1995;38:926-38.

19. Hsieh J-C, Belfrage M, Stone-Elander S, Hansson P, Ingvar M. Central representation of chronic ongoing neuropathic pain studied by positron emission tomography. Pain 1995;63:225-36.

20. Dileo C, Bradt J. Medical Music Therapy: A Meta-analysis \& Agenda for Future Research. Cherry Hill: Jeffrey Books, 2005.

21. Moayedi M, Davis KD. Theories of pain: From specificity to gate control. J Neurophysiol 2013;109:5-12.

22. Melzack R, Wall PD. Pain mechanisms: A new theory. Science 1965;150:971-9.

23. Melzack R. Pain and the neuromatrix in the brain. J Dental Educ 2001;65:1378-82.

24. Meyerson BA, Linderoth B. Mechanisms of spinal cord stimulation in neuropathic pain. Neurol Res 2000;22:285-92.

25. Fries P. A mechanism for cognitive dynamics: Neuronal communication through neuronal coherence. Trends Cogn Sci 2005;9:474-80.

26. Ward LM. Synchronous neural oscillations and cognitive processes. Trends Cogn Sci 2003;7:553-9.

27. Llinás R, Ribary U, Jeanmonod D, Kronberg, E, Mitra PP. Thalamocortical dysrhythmia: A neurological and neuropsychiatric syndrome characterized by magnetoencephalography. Proc Natl Acad Sci U S A 1999;96:15222-7.

28. Walton KD, Llinás RR. Central pain as a thalamocortical dysrhythmia. In: Kruger L, Light AR, eds. Translational Pain Research: From Mouse to Man. Boca Raton: CRC Press, 2010.

29. Bhatara AK, Levitin DJ, Tirovolas AK, Duan LM, Levy B. Perception of emotional expression in musical performance. J Exp Psychol Hum Percept Perform 2011;37:921-34.

30. Menon V, Levitin DJ. The rewards of music listening: Response and physiological connectivity of the mesolimbic system.

Neuroimage 2005;28:175-84.

31. Levitin DJ. The neural correlates of temporal structure in music. Music Med 2009;1:9-13

32. McKinney CH, Tims FC, Kumar AM, Kumar M. The effect of selected classical music and spontaneous imagery on plasma $\beta$-endorphin. J Behav Med 1997;20:85-99.

33. Kuhn D. The effects of active and passive participation in musical activity on the immune system as measured by salivary immunoglobulin A (SIgA). J Music Ther 2002;39:30-9.

34. Liégeois-Chauvel C, Peretz I, Babaï M, Laguitton V, Chauvel P. Contribution of different cortical areas in the temporal lobes to music processing. Brain 1998;121:1853-67

35. Peretz I, Zatorre RQ. Brain organization for music processing. Ann Rev Psychol 2005;56:89-114

36. Blood AJ, Zatorre RJ, Bermudez P, Evans AC. Emotional responses to pleasant and unpleasant music correlate with activity in paralimbic brain regions. Nat Neurosci 1999;2:382-7

37. Salimpoor VN, Benovoy M, Longo G, Cooperstock JR, Zatorre RJ. The rewarding aspects of music listening are related to degree of emotional arousal. PLoS ONE 2009;4:e7487.

38. Salimpoor VN, Benovoy M, Larcher K, Dagher A, Zatorre RJ. Anatomically distinct dopamine release during anticipation and experience of peak emotion to music. Nat Neurosci 2011;14:257-62.

39. Gangrade A. The effect of music on the production of neurotransmitters, hormones, cytokines, and peptides: A review. Music Med 2012;4:40-3.

40. Brandes VM, Terris D, Fischer C, et al. Receptive music therapy for the treatment of depression: A proof-of-concept study and prospective controlled trial of efficacy. Psychother Psychosom 2010;79:321-2

41. Erkkilä J, Punkanen M, Fachner J, et al. Individual music therapy for depression: Randomised controlled trial. Br J Psychiatry 2011;199:132-9.

42. Khalfa S, Bella SD, Roy M, Peretz I, Lupien SJ. Effects of relaxing music on salivary cortisol level after psychological stress. Ann N Y Acad Sci 2003;999:374-6.

43. Fukui $H$, Yamashita M. The effects of music and visual stress on testosterone and cortisol in men and women. Neuro Endocrinol Lett 2003;24:173-80.

44. Levitin DJ. This is Your Brain on Music. New York: Plume/Penguin, 2007.

45. Chanda M, Levitin DJ. The neurochemistry of music. Trends Cogn Sci 2013;17:179-93.

46. Möckel M, Röcker L, Störk T. Immediate physiological responses of healthy volunteers to different types of music: Cardiovascular, hormonal and mental changes. Eur J Appl Physiol 1994;68:451-9.

47. Möckel M, Stork T, Vollert J, et al. Stress reduction through listening to music: Effects on stress hormones, hemodynamics and mental state in patients with arterial hypertension and in healthy persons. Dtsch Med Wochenschr 1995;120:745-52.

48. Wigram, T. The effect of vibroacoustic therapy compared with music and movement based physiotherapy on multiply handicapped patients with high muscle tone and spasticity. In: Wigram T, Dileo C, eds. Music Vibration and Health. Cherry Hill: Jeffrey Books, 1997:69-85.

49. Karkkainen M, Mitsui J. The effects of sound based vibration treatment on the human mind and body: The physioacoustic method. J Int Soc Life Inf Sci 2006;24:155-9

50. Zheng A, Sakari R, Cheng SM, et al. Effects of a low-frequency sound wave therapy programme on functional capacity, blood circulation and bone metabolism in frail old men and women. Clin Rehabil 2009;23:897-908.

51. Chesky K, Rubin B, Frische E. The pain relieving effect of music vibration on rheumatoid arthitis patients as related to just music and placebo. International Society for Music Education Conference Abstracts, 1992.

52. Skille O. Vibro acoustic therapy. Music Therapy 1989;8:61-77.

53. Skille $\mathrm{O}$, Wigram $\mathrm{T}$. The effects of music, vocalization and vibrations on brain and muscle tissue: Studies in vibroacoustic therapy. In: Wigram T, Saperston B, West R, eds. The Art and Science of Music Therapy: A Handbook. London: Harwood Academic, 1995;23-57.

54. Burke M, Thomas K. Use of physioacoustic therapy to reduce pain during physical therapy for total knee replacement patients over age 55. In: Wigram T, Dileo C, eds. Music Vibration and Health. Cherry Hill: Jeffrey Books, 1997:99-106. 
55. Burke M. Effects of physioacoustic intervention on pain management of post operative gynecological patients. In: Wigram $\mathrm{T}$, Dileo C, eds. Music Vibration and Health. Cherry Hill: Jeffrey Books, 1997:107-23.

56. Skille O, Wigram T, Weeks L. Vibroacoustic therapy: The therapeutic effect of low frequency sound on specific physical disorders and disabilities. J Br Music Ther 1989;3:6-10.

57. Chesky KS, Russell IJ, Lopez Y, Kondraske GV. Fibromyalgia tender point pain: A double-blind, placebo-controlled pilot study of music vibration using the music vibration table. J Musculoskeletal Pain 1997;5:33-52.

58. Onieva-Zafra MD, Castro-Sanchez AM, Matarán-Peñarrocha GA, Moreno-Lorenzo C. Effect of music as nursing intervention for people diagnosed with fibromyalgia. Pain Manag Nurs 2013;14:e39-46.

59. Müller-Busch HC, Hoffmann P. Aktive Musiktherapie bei chronischen Schmerzen: Eine prospektive Untersuchung. Schmerz. 1997;11:91-100.

60. Leão ER, da Silva MJ. Música e dor crônica músculoesquelética: o potencial evocativo de imagens mentais. Rev Lat Am Enfermagem. 2004;12:235-41

61. Llinás RR, Ribary U, Jeanmonod D, Kronberg E, Mitra PP. Thalamocortical dysrhythmia: A neurological and neuropsychiatric syndrome characterized by magnetoencephalography. Proc Natl Acad Sci U S A 1999;96:15222-7.

62. Llinás R, Ribary U, Jeanmonod D, et al. Thalamocortical dysrhythmia I: Functional and imaging aspects. Thalamus \& Related Systems 1 2001;237-44

63. Schmidt S, Naranjo JR, Brenneisen C, et al. Pain ratings, psychological functioning and quantitative EEG in a controlled study of chronic back pain patients. PLoS One 2012;7:1-11.

64. Sarnthein J, Jeanmonod D. High thalamocortical theta coherence in patients with neurogenic pain. NeuroImage 2008;39:1910-7.

65. Stern J, Jeanmonod D, Sarnthein J. Persistent EEG overactivation in the cortical pain matrix of neurogenic pain patients. NeuroImage 2006;31:721-31.

66. Walton KD, Dubois M, Llinás RR. Abnormal thalamocortical activity in patients with complex regional pain syndrome (CRPS) type I. Pain 2010;150:41-51.

67. Cardoso-Cruz H, Sameshima K, Lima D, Galhardo V. Dynamics of circadian thalamocortical flow of information during a peripheral neuropathic pain condition. Front Integr Neurosci 2011;5:1-19.

68. Jensen KB, Loitoile R, Kosek E, et al. Patients with fibromyalgia display less functional connectivity in the brain's pain inhibitory network. Mol Pain 2012;8:32.

69. Patel A. A new approach to the cognitive neuroscience of melody. In: Peretz I, Zatorre R, eds. The Cognitive Neuroscience of Music. Oxford: Oxford University Press 2003:325-45.

70. Ross B, Jamali S, Miyazaki T, Fujioka T. Synchronization of beta and gamma oscillations in the somatosensory evoked neuromagnetic steady-state response. Exper Neurol 2013;245:40-51.

71. Jamali S, Fujioka T, Ross B. Neuromagnetic beta and gamma oscillations in the somatosensory cortex after music training in healthy older adults and a chronic stroke patient. Clin Neurophysiol 2014;125:1213-22.

72. Jamali, S, Ross, B. Somatotopic finger mapping using MEG: Toward an optimal stimulation paradigm. Clin Neurophysiol 2013;124:1659.

73. Herrmann CS. Human EEG responses to $1-100 \mathrm{~Hz}$ flicker: Resonance phenomena in visual cortex and their potential correlation to cognitive phenomena. Exp Brain Res 2001;137:346-53.
74. Birca A, Carmant L, Lortie A, Lassonde M. Interaction between the flash evoked SSVEPs and the spontaneous EEG activity in children and adults. Clin Neurophysiol 2006;117:279-88.

75. Pastor MA, Artieda J, Arbizu J, Valencia M, Masdeu JC. Human cerebral activation during steady-state visual-evoked responses. J Neurosci 2003;23:11621-7.

76. Llinás R, Ribary U. Coherent $40-\mathrm{Hz}$ oscillation characterizes dream state in humans. Proc Natl Acad Sci USA 1993;90:2078-81.

78. Ekici G, Bakar Y, Akbayrak T, Yuksel I. Comparison of manual lymph drainage therapy and connective tissue massage in women with fibromyalgia: A randomized controlled trial. J Manipulative Physiol Ther 2009;32:127-33.

78. Wolfe F, Clauw DJ, Fitzcharles MA, et al. The American College of Rheumatology preliminary diagnostic criteria for fibromyalgia and measurement of symptom severity. Arthritis Care Res (Hoboken). 2010;62:600-10.

79. Skille O. Fibro Recording. VibroAcoustic Solutions. <http://avigaili. wix.com/olav\#! vibroacoustic-solutions $>$ (Accessed November 10, 2013).

80. Bennett R. The Fibromyalgia Impact Questionnaire (FIQ): A review of its development, current version, operating characteristics and uses. Clin Exp Rheumatol 2005;23(5 Suppl 39):S154-62.

81. Jenkins CD, Stanton BA, Niemcryk SJ, Rose RM. A scale for the estimation of sleep problems in clinical research. J Clin Epidemiol 1988;41:313-21.

82. Pollard CA. Preliminary validity study of the pain disability index. Percept Mot Skills 1984;59:974.

83. Tait RC, Chibnall JT, Krause S. The Pain Disability Index: Psychometric properties. Pain 1990;40:171-82.

84. Wennemer HK, Borg-Stein J, Gomba L, et al. Functionally oriented rehabilitation program for patients with fibromyalgia: Preliminary results. Am J Phys Med Rehabil 2006;85:659-66.

85. Marcus DA, Bernstein CD, Haq A, Breuer P. Including range of outcome targets offers a broader view of fibromyalgia treatment outcome: Results from a retrospective review of multidisciplinary treatment. Musculoskeletal Care 2014;12:74-81.

86. Willis WD. The somatosensory system, with emphasis on structures important for pain. Brain Res Rev 2007;55:297-313.

87. Gamsa A. The role of psychological factors in chronic pain: I. A half century of study. Pain 1994;57:5-15.

88. Apkarian AV, Bushnell MC, Treede RD, Zubieta JK. Human brain mechanisms of pain perception and regulation in health and disease. Eur J Pain 2005;9:463-84.

89. Kokebie R, Aggarwal R, Kahn S, Kartz RS. Muscle tension is increased in fibromyalgia: Use of a pressure gauge. Abstract 1935, American College of Rheumatology 2008 Annual Scientific Meeting. October 24 to 29, 2008; San Francisco, California.

90. Kulshreshtha P, Deepak KK. Autonomic nervous system profile in fibromyalgia patients and its modulation by exercise: A mini review. Clin Physiol Funct Imaging 2013;33:83-91.

91. Carolyn R, McMakin MA, Oschman J. Visceral and somatic disorders: Tissue softening with frequency-specific microcurrent. J Altern Complement Med 2013;19:170-7.

92. Theadom A, Cropley M, Humphrey KL. Exploring the role of sleep and coping in quality of life in fibromyalgia. J Psychosom Res 2007;62:145-51.

93. Bigatti SM, Hernandez AM, Cronan TA, Rand KL. Sleep disturbances in fibromyalgia syndrome: Relationship to pain and depression. Arthritis Rheum 2008;59:961-7. 


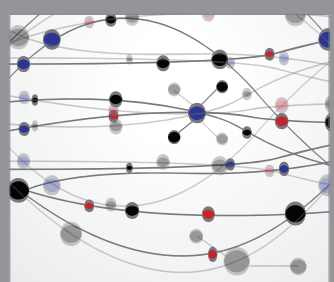

The Scientific World Journal
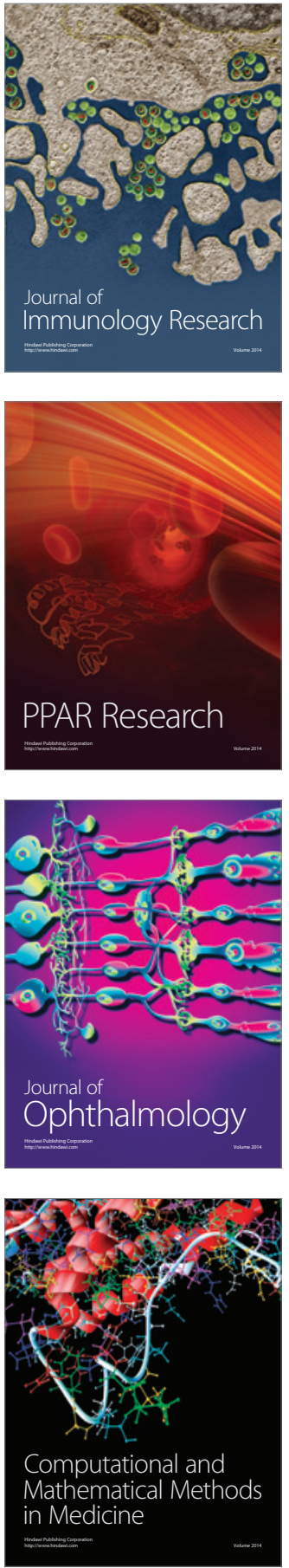

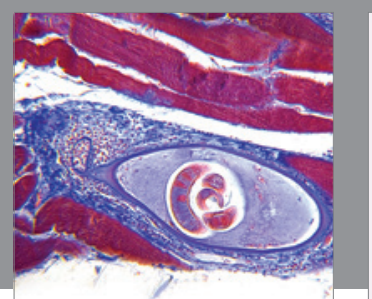

Gastroenterology Research and Practice

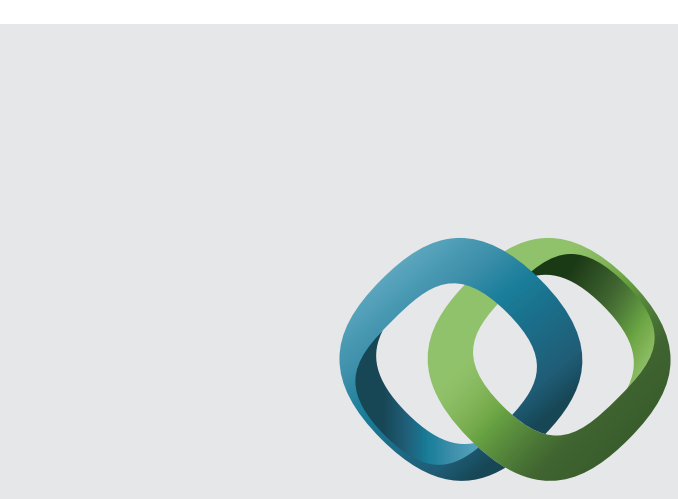

\section{Hindawi}

Submit your manuscripts at

http://www.hindawi.com
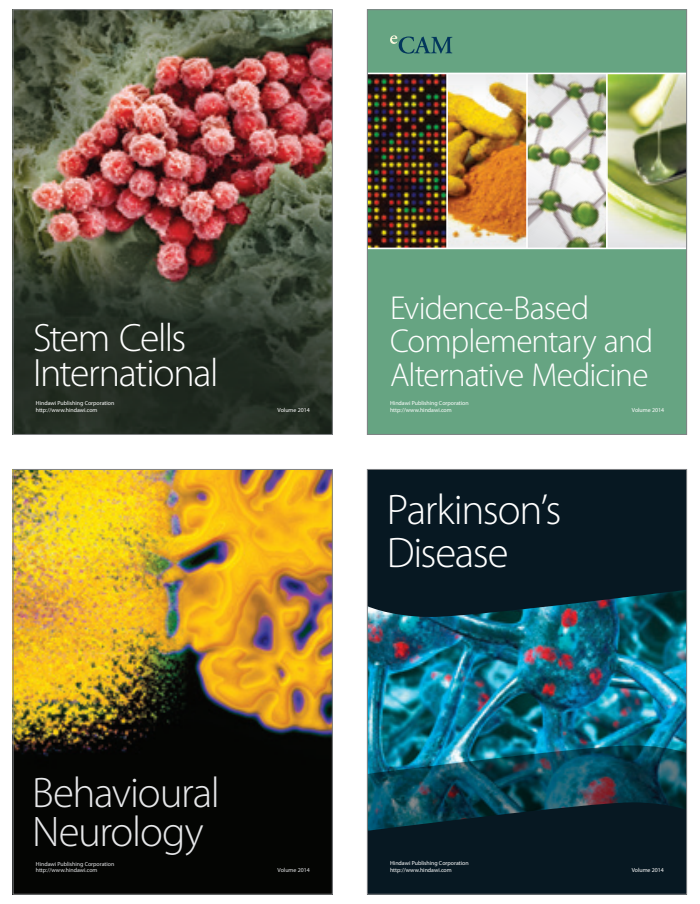
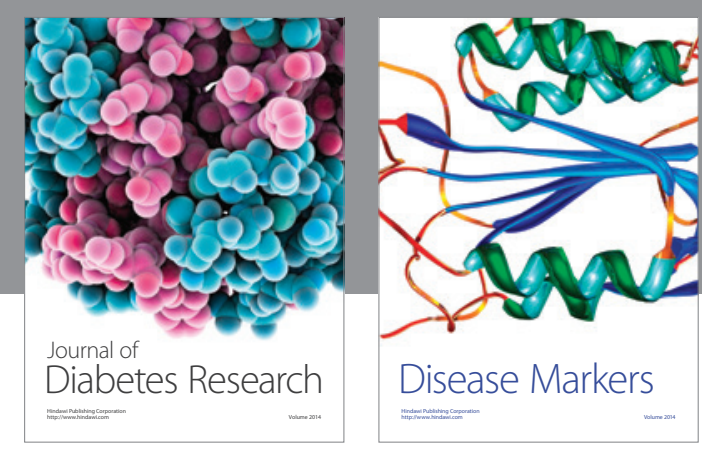

Disease Markers
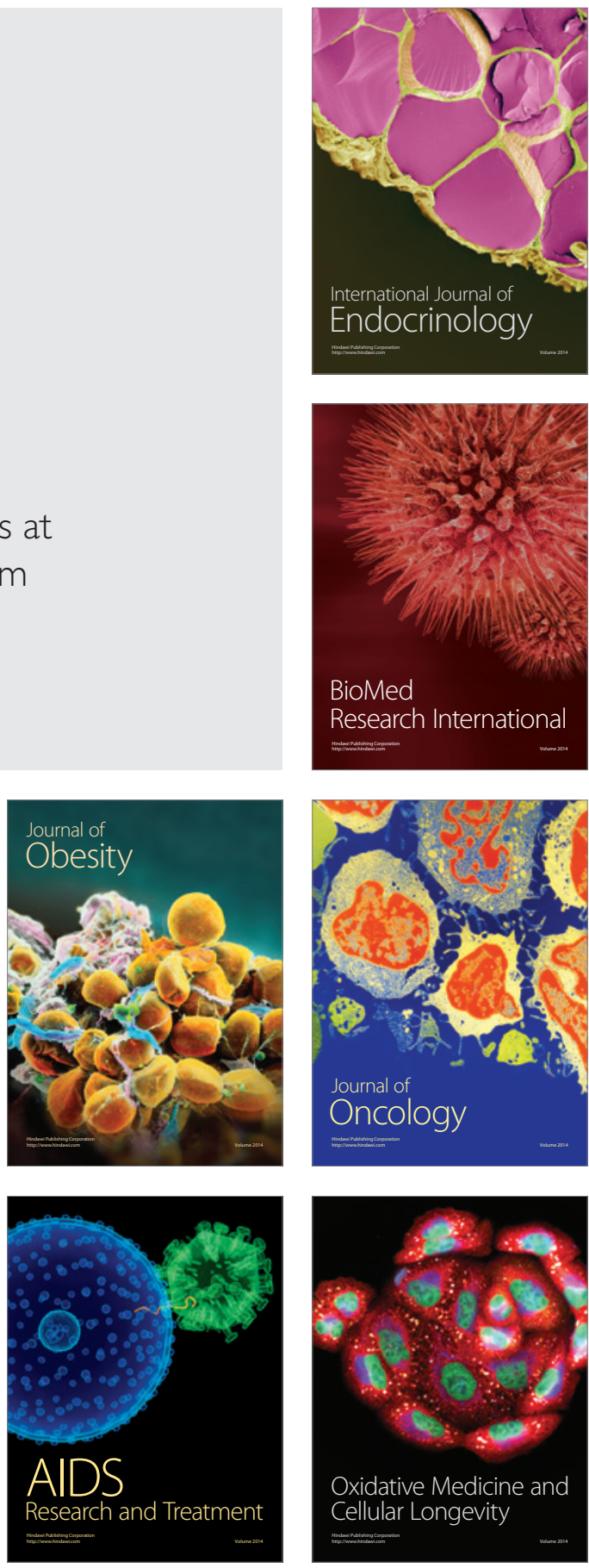